\title{
Challenges in lung transplantation
}

\author{
Desafios do transplante pulmonar
}

Fábio Biscegli, Paulo Manuel Pêgo-Fernandes

Lung transplantation is a therapeutic alternative that has been in use since the beginning of the 1960s, although the initial results were less than promising. After the advent of cyclosporine in the 1980s, lung transplantation came to be viewed as a real alternative in certain countries. In Brazil, the debut of lung transplantation was slow to come about, and the procedure was initially restricted to a handful of facilities. However, in recent years, the number of lung transplantations performed in Brazil has increased, as has the quality of the results. Nevertheless, every success has its price, and this increase has led to a greater number of candidates for the surgery, thereby lengthening the lung transplant waiting list. This phenomenon is not restricted to Brazil. Barr et al. ${ }^{(1)}$ reported that the number of patients on the waiting list for a lung transplant in the United States has increased progressively due to improvements in donor management, surgical techniques, immunosuppression and postoperative care, all of which have made lung transplantation a procedure that is well accepted as a treatment for advanced lung disease. The authors also reported that, at the end of 2003, the number of patients on the waiting list in the United States was 3888, which represents an increase of $147 \%$ in relation to 1993 . Those same authors stated that, over the same ten-year period, the number of organs (donor lungs) available increased by only $51 \%$, thereby creating a disparity between the number of donors and the number of recipients. Certainly, although perhaps in different proportions, this has occurred in Brazil. At the Heart Institute, located in the city of São Paulo, we have seen a progressive increase in the number of potential recipients. Consequently, the number of lung transplants performed at our Institution has increased year after year. However, the mortality rate among the patients on the waiting list has also increased, since the increase in the number of donors has not kept pace with that of the number of potential recipients. Worldwide, this phenomenon has prompted the search for alternatives. One such alternative is the use of marginal donors, which requires expanding the donor criteria. ${ }^{(2,3)}$ There has been considerable discussion of the pros and cons of using such donor lungs. Although this increases the number of transplants performed, it also worsens outcomes. There is currently a tendency toward relaxing the donor criteria for all organs. In the case of lung transplantation, the criteria initially described as ideal were based on a small number of procedures and are practically to put into practice in the current scenario.

The authors of a recent study described the ex vivo reconditioning of donor lungs initially rejected by transplantation centers, ${ }^{(4)}$ and the preliminary results obtained were promising. The use of this technique could increase the number of donor lungs available.

In attempting to reduce mortality among patients on lung transplant waiting lists, transplantation centers have begun to institute prioritization criteria. In Brazil, potential recipients of certain organs, such as liver and heart transplant candidates, are currently given priority on the basis of disease severity. In the United States, until a few years ago, candidates received transplants on a first-come, first-served basis, those having been on the list the longest being given preference. This is currently the policy regarding lung transplantation in Brazil. Officials in the United States recently established prioritization criteria for lung transplantation. These new criteria take into account various factors, such as disease severity, natural rate of progression of the underlying disease and the benefit of transplantation versus allowing the disease to run its course. The discussion as to whether this is the best system is ongoing. ${ }^{(5)}$ However, judging by our current situation, we believe that such prioritization criteria will soon be implemented in Brazil.

Within the context of serving a greater number of patients and reducing waiting list mortality rates, living lobar lung transplant presents a real alternative for a select group of patients. The study conducted by Camargo et al. and published in this issue of the Brazilian Journal of Pulmonology relates a novel experience with a sufficient number of patients in Brazil. The authors analyze the risks for the organ donors, all of whom were previously healthy and in no need of any treatment whatsoever. The same authors found that, despite the fact that there were no deaths among the donors, there was a significant degree of donor morbidity. In addition, they reported that, in recipients with advanced lung disease, the risks related to transplantation are high, which can make donor candidates uncomfortable with the prospect of undergoing a surgical procedure that might not provide the intended benefit. However, in such cases, the recipient has no chance of 
survival without undergoing the procedure. This is obviously an equation that demands the intense participation of all involved in order to decide upon the proper course of action.

One group of authors made this type of transplantation a viable alternative in 1994 and have subsequently dedicated much of their efforts to improving the technique..$^{(7,8)} \ln 2005$, that same group published an editorial in which they performed a critical analysis of the technique based on the results obtained to date and speculated regarding future trends. ${ }^{(1)}$ They stated that, despite the fact that they had performed the procedure in 273 donors without any donor deaths, there is a constant fear that this will occur. In follow-up tests of lung function in those donors, the authors noted a slight decline in lung capacity, although this did not affect donor quality of life. They concluded that, although it is undesirable to expose healthy individuals to surgical risk, living lobar lung transplant represents a viable option. The procedure provides good benefits, in terms of function, to the recipients and should be considered in patents that might die while awaiting a lung from a deceased donor. It should also be considered in recipients for whom, due to individual characteristics, appropriate grafts are difficult to obtain.

As previously stated, the implementation of prioritization criteria in the United States has reduced the need for living lobar lung transplant, since the most critical patients are the first to receive organs from deceased donors. Lung transplantation is certainly fascinating field, in which the development of new technologies, new information and constant adaptation of criteria are all facets of the process. These changes force us to continually review and update our knowledge. Fortunately, Brazil now has state-of-the-art facilities for lung transplantation, providing an efficient and efficacious alternative for patients with advanced lung disease.

\author{
Fabio Biscegli \\ Full Professor in the Department \\ of Thoracic Surgery \\ Central Institute of the \\ Hospital das Clinicas - Heart Institute - \\ University of São Paulo School of Medicine \\ Paulo Manuel Pêgo-Fernandes \\ Associate Professor in the Department \\ of Cardiology and Pulmonology at the \\ University of São Paulo School of Medicine
}

\section{References}

1. Barr ML, Schenkel FA, Bowdish ME, Starnes VA. Living donor lobar lung transplantation: current status and future directions. Transplant Proc. 2005;37(9):3983-6.

2. Pierre AF, Sekine Y, Hutcheon MA, Waddell TK, Keshavjee SH. Marginal donor lungs: A reassessment. J Thorac Cardiovasc Surg. 2002;123(3):421-7; discussion, 427-8.

3. Orens JB, Boehler A, de Perrot M, Estenne M, Glanville AR, Keshavjee $S$, et al. A review of lung transplant donor acceptability criteria. J Heart lung Transplant. 2003;22(11):1183-200. Review. No abstract available.

4. Steen S, Ingemansson R, Eriksson L, Pierre L, Algotsson $\mathrm{L}$, Wierup $\mathrm{P}$, et al. First human transplantation of a nonacceptable donor lung after reconditioning ex vivo. Ann Thorac Surg. 2007;83(6):2191-4.

5. Garrity ER, Moore J, Mulligan MS, Shearon TH, Zucker MJ, Murray S. Heart and lung transplantation in the United States, 1996-2005. Am J Transplant. 2007;7(5 Pt 2):1390-403.

6. Camargo SM, Camargo JJ, Schio SM, Sánchez LB, Felicetti JC, Moreira JS, et al. Complications related to lobectomy in living lobar lung transplant donors. J. Bras. Pneumol. 2008;34(5): 256-63.

7. Starnes VA, Barr ML, Cohen RG. Lobar transplantation: indications, technique, and outcome. J Thorac Cardiovasc Surg. 1994;108(3):403-10; discussion, 410-1.

8. Bowdish ME, Barr ML, Schenkel FA, Woo MS, Bremner RM, Horn MV, et al. A decade of living lobar lung transplantation: perioperative complications after 253 donor lobectomies. Am J Transplant. 2004;4(8):1283-8. 